\title{
Serum Biochemistry of Albino Wistar Rats Treated With Tobacco Diet
}

\author{
*Kebe E. Obeten, Roseline P. Ekpefiong, Charles C. Mfem \\ *Department of Anatomy, University of Calabar, Calabar \\ Department of Physiology, University of Calabar, Calabar
}

\begin{abstract}
This study evaluated some serum biochemistry in albino wistar rats treated with tobacco diet. Twenty wistar rats weighing between 80-190g were randomly assigned into two groups of ten (10) each. Group A were fed normal rat chow, while group B were fed with tobacco diet of $80 \mathrm{~g}$ of animal chow mixed with $20 \mathrm{~g}$ of granulated tobacco. They were fed for 28 days and had free access to drinking water. The result showed that the mean total protein concentration in the tobacco group $(18.40 \pm 2.74 \mathrm{~g} / \mathrm{l})$ was not significantly different $(P<0.05)$ when compared to the control. Glucose was significantly lower compared to the control while the lipid concentration was significantly higher $(P<0.001)$ when compared to the control group.

Intake of tobacco, is capable of altering the protein, lipid and blood glucose concentration indicating that tobacco consumption may be dangerous to health.

Key words: Tobacco, Wistar rats, serum biochemistry
\end{abstract}

\section{Introduction}

Tobacco is used in two major forms: the smokers and the smokeless. The smokeless tobacco has different nature names according to Thompson (2008), these are: Ntsu in South Africa, Toombak in Sudan, Shammah in South Arabia, plug chew in the United States. In Nigeria, the common names are Anwuru in Igbo, Taba in Yoruba and Hausa languages.

Tobacco is the single greatest cause of preventable death globally (WHO, 2008) Tobacco use leads most commonly to diseases affecting the heart, liver and lungs, with smoking being a major risk factor for heart attacks, strokes, chronic obstructive pulmonary disease (COPD) (including emphysema and chronic bronchitis), and cancer (particularly lung cancer, cancers of the larynx and mouth, and pancreatic cancer). It also causes peripheral vascular disease and hypertension. The effects depend on the number of years that a person smokes and on how much the person smokes. Starting smoking earlier in life and smoking cigarettes higher in tar increases the risk of these diseases. Also, environmental tobacco smoke, or secondhand smoke, has been shown to cause adverse health effects in people of all age, (Vainio, 1987). Cigarettes sold in underdeveloped countries tend to have higher tar content, and are less likely to be filtered, potentially increasing vulnerability to tobaccorelated disease in these regions (Nichter et al.,1991)

The World Health Organization (WHO) estimates that tobacco caused 5.4 million deaths in 2004 (WHO, 2008) and 100 million deaths over the course of the 20th century (WHO, 2008) Similarly, the United States Centers for Disease Control and Prevention describes tobacco use as "the single most important preventable risk to human health in developed countries and an important cause of premature death worldwide". Several countries have taken measures to control the consumption of tobacco with usage and sales restrictions as well as warning messages printed on packaging.

Smoke contains several carcinogenic pyrolytic products that bind to DNA and cause many genetic mutations. There are more than 45 known or suspected chemical carcinogens in cigarette smoke (Fowles et al., 2003) Tobacco also contains nicotine, which is a highly addictive psychoactive drug. When tobacco is smoked, nicotine causes physical and psychological dependency. Tobacco use is a significant factor in miscarriages among pregnant smokers, and it contributes to a number of other threats to the health of the fetus such as premature births and low birth weight and increases by 1.4 to 3 times the chance for Sudden Infant Death Syndrome (SIDS) (U.S. Department of Health and Human Services, 2006).

Glucose is a major source of energy for most cells of the body, including those in the brain. Carbohydrates (or carbs) are found in fruit, cereal, bread, pasta, and rice. They are quickly turned into glucose in your body. This raises your blood glucose level (Buse, 2011). Serum protein electrophoresis (SPEP) is a laboratory test that examines specific proteins in the blood called globulins. Blood must first be collected, usually into an airtight vial or syringe. Electrophoresis is a laboratory technique in which the blood serum (the fluid portion of the blood after the blood has clotted) is placed into a gel, or into liquid in a capillary tube, and exposed to an electric current to separate the serum protein components into five major fractions by size and electrical charge: serum albumin, alpha-1 globulins, alpha-2 globulins, beta globulins, and gamma globulins (Hoang et al., 1999).

Blood lipids (or blood fats) are lipids in the blood, either free or bound to other molecules. They are mostly transported in a protein capsule, and the density of the lipids and type of protein determines the fate of the particle and its influence on metabolism. The concentration of blood lipids depends on intake and excretion 
from the intestine, and uptake and secretion from cells. Blood lipids are mainly fatty acids and cholesterol. Hyperlipidemia is the presence of elevated or abnormal levels of lipids and/or lipoproteins in the blood, and is a major risk factor for cardiovascular disease (Harvey, 2003)

\section{Materials and methods}

Thirty (30) rats weighing 80-190g were procured from the animal house, Department of physiology, University of Calabar, Calabar, Nigeria. The rats were maintained under normal laboratory conditions of temperature, humidity and light for a period 2 weeks in the animal holdings of the Department of Human Anatomy, University of Calabar, Calabar, Nigeria, before commencement of experiment.

Tobacco leaves was bought from Ugep in Yakurr Local Government Area of Cross River State. The leaves were washed and sundried for a few days. After which they were placed in an Astell Hearson Microwave oven at a temperature of $40-50^{\circ} \mathrm{c}$ in the Department of Anatomy, University of Calabar, Calabar, Nigeria, till the leaves were crispy and easy to blend. The leaves were removed and grounded in a blender to find powder. $80 \mathrm{~g}$ of the animal chow was mixed with $20 \mathrm{~g}$ of the powdered tobacco and administered to each animal in tobacco group once daily for 28 days.

\section{Discussion}

Chronic consumption of tobacco diet reduced serum glucose in the tobacco treated group, this may be due to a component of tobacco which stimulates digestion and absorption of glucose. The tobacco consumption has no significant effect on serum protein level, whereas chronic consumption of tobacco significantly lowered the appearance of protein in the body. This is suggestive that tobacco may have a stimulating effect on digestion and absorption of protein in the body. Hence, chronic intake of tobacco should be discouraged since it reveals alteration of protein, lipid and glucose level in the treated groups.

\section{Effect of glucose concentration}

\section{Results}

The mean glucose concentration in the tobacco group $(0.42 \pm 0.02 \mathrm{mmol} / \mathrm{L})$ was significantly lower $(\mathrm{P}<0.001)$ when compared with that in control group $(0.82 \pm 0.02 \mathrm{mmol} / \mathrm{L})$. Figure 1

\section{Effect of lipid concentration}

The mean lipid concentration in tobacco group $(0.09 \pm 0.01 \mathrm{~g})$ was significantly higher $(\mathrm{P}<0.001)$ when compared with control group. Figure 2.

\section{Effect of total protein concentration}

The mean total protein concentration in the tobacco group $(18.40 \pm 2.74 \mathrm{~g} / \mathrm{L})$ was not significantly different when compared with control group $(16.00 \pm 0.89 \mathrm{~g} / \mathrm{L})$. figure 3

\section{FIGURES}

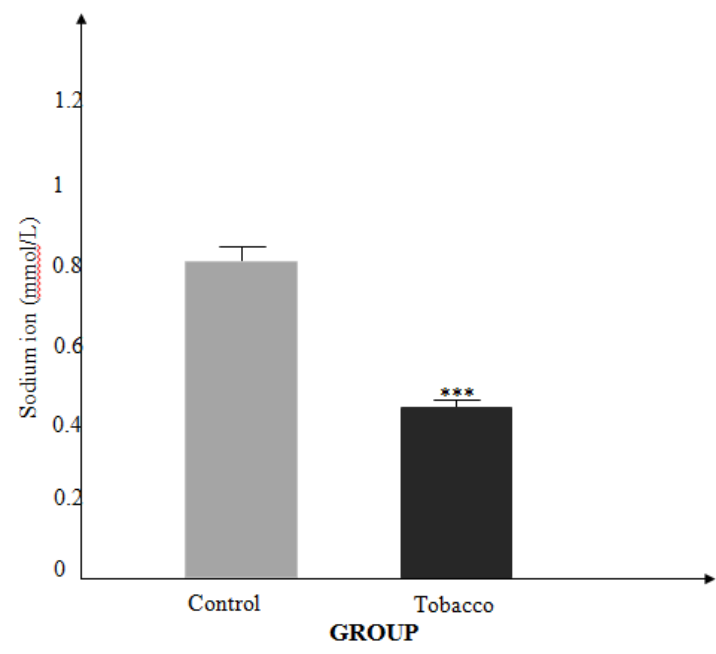

Figure 1: comparison of mean glucose concentration in the different experimental groups. Values are mean \pm SEM, $n=5$.

$* * * \mathbf{P}<0.01$ vs control 


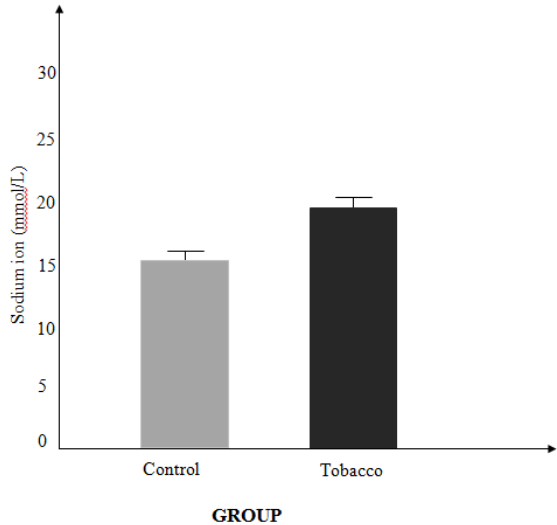

Figure 2: Comparison of mean protein concentrations in the different experimental groups. Values are mean \pm SEM, $n=5$

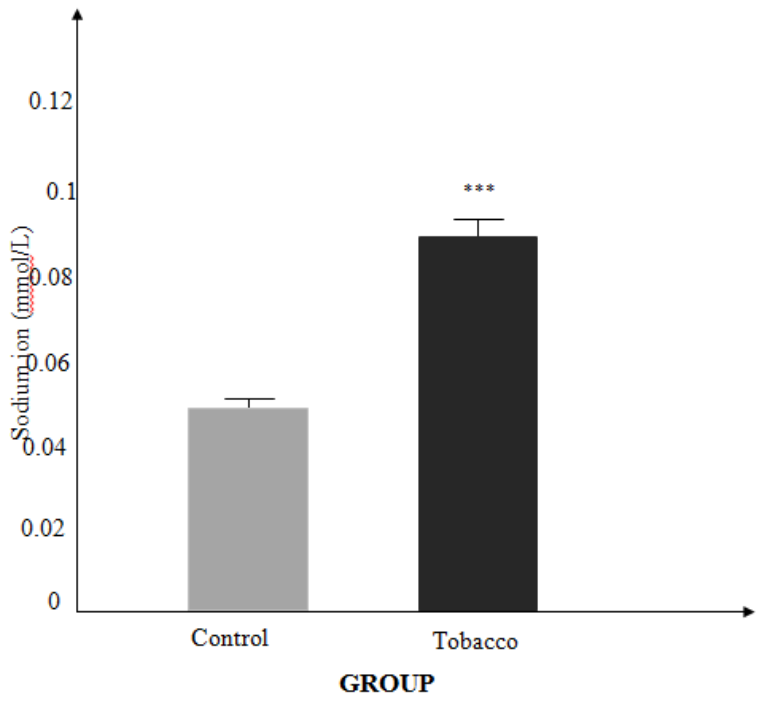

Figure 3: Comparison of mean lipid concentrations in the different experimental groups. Values are mean \pm SEM, $n=5$ $* * * \mathbf{P}<0.001$ vs control

\section{References}

[1]. Buse JB \& Polonsky KS,Burant C (2011). Type 2 diabetes mellitus. In: Melmed S, Polonsky KS,Larsen PR, Kronenberg HM, Larsen PR, eds.Williams Textbook of Endocrinology. 12th ed. Philadelphia,Pa: Saunders Elsevier;:chap 31.

[2]. Fowles J, Dybing E (2003). "Application of toxicological risk assessment principles to the chemical constituents of cigarette smoke". Tob Control 12 (4): 424-30. doi:10.1136/tc.12.4.424. PMC 1747794. PMID 14660781.

[3]. Hoang, Mai P; Baskin, Leland B; Wians, Frank H (1999). "Bisalbuminuria in an adult with bisalbuminemia and nephrotic syndrome". Clinica Chimica Acta 284 (1): 101-7.

[4]. Molecular cell biology. Lodish, Harvey F. (2003) $5^{\text {th }}$ ed.:- New York : W. H. Freeman and Co., p321.

[5]. Nichter M, Cartwright E (1991). "Saving the Children for the Tobacco Industry". Medical Anthropology Quarterly 5 (3): $236-56$. doi:10.1525/maq.1991.5. 3.02a00040. JSTOR 648675.

[6]. The health consequences of involuntary exposure to tobacco smoke: a report of the Surgeon General" (PDF). Atlanta, U.S., page 93: U.S. Department of Health and Human Services, Centers for Disease Control and Prevention, National Center for Chronic Disease Prevention and Health Promotion, Office on Smoking and Health. 2006. Retrieved 2013-12-10.

[7]. Thomson M. (2008). Health effects of smokeless Tobacco products. SCENIHR (Scienstific Committee on Emerging and Newly Identified Health Risks) paper Brussel.

[8]. Vainio H (1987). "Is passive smoking increasing cancer risk?". Scand J Work Environ Health 13 (3): 193-6. doi:10.5271/sjweh.2066. PMID 3303311

[9]. WHO Report on the Global Tobacco Epidemic. World Health Organization. 2008

[10]. World Health Organization (2008). The Global Burden of Disease (2004 Update ed.). Geneva: World Health Organization. ISBN 92-4-156371-0.

[11]. World Health Organization (2008). WHO Report on the Global Tobacco Epidemic 2008: The MPOWER Package. Geneva: World Health Organization. ISBN 92-4-159628-7 